\title{
Primary Exploration of Radial Nerve is Not Required for Radial Nerve Palsy while Treating Humerus Shaft Fractures with Unreamed Humerus Nails (UHN)
}

\author{
G. Grass ${ }^{\S, 1}$, K. Kabir ${ }^{\S, 2}$, J. Ohse $^{2}$, C. Rangger ${ }^{2}$, L. Besch $^{3}$ and G. Mathiak ${ }^{*}, 3$ \\ ${ }^{I}$ Geschäftsstelle der Ethik-Kommission der Medizinischen Fakultät der Universität zu Köln, Kerpener Str. 62, D-50937 \\ Köln, Germany \\ ${ }^{2}$ Klinik und Poliklinik für Orthopädie und Unfallchirurgie, Universitätsklinikum Bonn, Siegmund-Freud-Str. 25, \\ D-53105 Bonn, Germany \\ ${ }^{3}$ Klinik für Unfallchirurgie, Universitätsklinikum Schleswig-Holstein, Campus Kiel, Arnold-Heller-Str. 9, D-24105 Kiel, \\ Germany
}

\begin{abstract}
Background: Today, humerus nails have become the surgical method of choice in the treatment of humerus shaft fractures. Whether or not the radial nerve should be intraoperatively examined by default in case of primary paresis is currently under discussion.

Patients and Methods: Clinical findings from 38 patients with humeral shaft fractures surgically treated with unreamed humerus nail (UHN) at the Department of Accident Surgery, University Clinics Bonn, Germany, between 2000 and 2003 were retrospectively assessed. Constant Score was applied for evaluation of functional results.

Results: In $40 \%$ of patients, primary radial nerve paresis was present. This was especially common after high energy trauma (e.g. traffic accident) and significantly increased in fractures of the middle third. In $93 \%$ of cases, spontaneous remission of motor and sensory loss was observed. No iatrogenic radial nerve impairment occurred.

Conclusion: Due to the high rates of spontaneous remissions of radial nerve palsy after treatment with UHN in humerus shaft fractures, primar exploration of the radial nerve does not appear to be necessary.
\end{abstract}

Keywords: Humerus shaft fracture, radial nerve, palsy, unreamed humerus nail (UHN), constant score.

\section{INTRODUCTION}

In accident surgery, humerus shaft fracture is not very common, with an incidence of $1 \%$ in relation to fractures of all limbs. Due to the radial nerve's anatomical proximity to the humerus shaft, concomitant injuries of this nerve are of specific interest. In their systematic review, Shao and coworkers reported on 532 cases of radial nerve palsy in 4517 humerus shaft fractures [1] corresponding to a rate of $11.8 \%$.

Palsy of the radial nerve leads to considerable impairment of day-to-day functions. For example, opening of the hand for grasping of objects becomes impossible.

In the last 50 years, therapy of humerus shaft fracture has been widely discussed. A distinct trend towards surgical treatment has been noted since the 1980s. While in 1964, Böhler still postulated conservative treatment of this fracture [2], by 1991, more than $50 \%$ of humerus fractures were treated surgically [3], mostly with osteosynthetic plating with mandatory examination of the radial nerve. Prevalence

*Address correspondence to this author at the Klinik für Unfallchirurgie UKSH, Campus Kiel/Chirurgie-Orthopädie Heikendorf, Teichtor 23, D24226 Heikendorf/Kiel, Germany; Tel: 0431/243548; Fax: 0431/242696;

E-mail: guenther.mathiak@web.de

${ }^{\S}$ Both authors contributed equally to the publication. of less invasive nail techniques, introduced for the humerus by Seidel and co-workers [4], and subsequent improvement of nail design resulted in a paradigm shift in the last decade. However, controlled prospective studies comparing conservative and surgical treatment of humerus shaft fractures are still lacking.

Aim of the present study is to analyze incidence of radial palsy following humerus shaft fracture treated with unreamed humerus nail and whether palsy remission occurs without intraoperative examination of the radial nerve.

\section{PATIENTS AND METHODS}

The present study included all patients with humeral shaft fractures surgically treated with unreamed humerus nail (UHN) at the Department of Accident Surgery, University Clinics Bonn, Germany, between 2000 and 2003. Retrospective analysis was based on medical records, surgical reports and radiograms.

Demographic data, accident details and information on secondary interventions and extent of trauma were obtained from patients' medical records. Data from surgical reports included indication for surgery, time and duration of surgery and intra- and postoperative complications. In addition, extent of soft tissue damage was documented, in closed fractures according to Tscherne and Oestern [5] and in open 
fractures according to Gustilo [6]. Fracture classification was assessed on the basis of the AO Classification of Fractures.

Twenty-four patients were included in long-term followup and interviewed regarding subjective complaints and personal assessment of treatment results. Functional examination included: range of motion the shoulder and elbow joint, measured according to the neutral- 0 method. Documentation of incidence of radial nerve palsy, affected areas and remission was of specific interest. Constant Score was used to record functional results [7].

All examinations were carried out according to the Declaration of Helsinki as revised by the World Medical Association and respective legal regulations.

Statistical data assessment was performed using SPSS 13.0. Frequency distribution was examined for statistical significance with the chi-square test. Differences between groups regarding parametric data were established with the $t$ test, non-parametric group comparisons with the MannWhitney-U-Test. All statistical analyses were performed exploratively. A $p$-value $\leq 0.05$ was considered statistically significant.

\section{RESULTS}

Between 24 Nov 2000 and 7 March 2003, 38 patients (20 female $(53 \%)$ and 18 male $(47 \%)$ ) with humeral shaft fractures were treated with unreamed humerus nails (UHN) at the Department of Accident Surgery, University Clinics Bonn, Germany. Average age was 53 years (range $16-92$ years).

In 13 patients, the fracture occurred as part of a polytrauma. The remaining 25 cases were monotraumas. In male patients, $79 \%$ of fractures resulted from high energy traumas, e.g. traffic accidents of fall from a great height (Table 1). In female patients, low energy traumas, such as pedestrian falls or accidents in the home, were more common. However, this difference was statistically not significant $(\mathrm{p}=0.095)$. The most common cause of accident was traffic accident in 16 patients $(67 \%)$, followed by accidents in the home in about one quarter of patients $(\mathrm{n}=$ 9 ). In seven patients (18\%), the fracture occurred spontaneously due to malignant underlying disease. In three patients (8\%), the fractures resulted from a fall from a great height or a jump for suicidal reasons. In two patients (5\%), sporting accidents lead to the humeral shaft fracture.

The right arm was affected in 17 patients (45\%), while in 21 patients $(55 \%)$, it was the left arm. Most of the fractures $(58 \%)$ were localized at the middle third, while five fractures $(13 \%)$ occurred at the distal third and in four cases $(11 \%)$, at the proximal third or the intersection of proximal and middle third, respectively. One (3\%) segmental fracture was recorded. According to the AO Classification of Fractures, the majority of fractures $(55 \%)$ were simple ones. The A3 fracture was followed by the wedge fracture with spiral wedge (24\%).

There was no primary infected injury. In $84 \%$ of patients $(\mathrm{n}=32)$, the fracture was closed, while in $16 \%(\mathrm{n}=6)$, it was an open one.

\section{Radial Nerve Palsy}

On admission, 15 (40\%) patients with (all with closed fractures) presented primary radial nerve palsy (Table 2). No damage to the musculocutaneous nerve of the arm was noted in any of these patients.

\section{Table 1. Cause of Accident}

\begin{tabular}{|l|c|c|c|c|}
\hline \multirow{2}{*}{ Cause of Accident } & \multicolumn{2}{|c|}{ Male } & \multicolumn{2}{c|}{ Female } \\
\cline { 2 - 5 } & $\mathbf{n}$ & $\mathbf{\%}$ & $\mathbf{n}$ & $\mathbf{\%}$ \\
\hline \hline Traffic accident & 9 & 50 & 7 & 35 \\
\hline driver & 2 & 11 & 3 & 15 \\
\hline motorcyclist & 5 & 28 & 0 & 0 \\
\hline cyclist & 1 & 6 & 1 & 5 \\
\hline pedestrian & 1 & 6 & 3 & 15 \\
\hline Sport & & & 2 & 10 \\
\hline Household & 3 & 17 & 6 & 30 \\
\hline Accident at work & & & 1 & 5 \\
\hline Pathological fracture & 4 & 22 & 3 & 15 \\
\hline Fall/jump from great height & 2 & 11 & 1 & 5 \\
\hline
\end{tabular}

Table 2. Concomitant Neurovascular Injuries

\begin{tabular}{|l|c|c|}
\hline \multicolumn{1}{|c|}{ Concomitant Neurovascular Injuries } & Number & Percent \\
\hline \hline No concomitant neurovascular injuries & 22 & 58 \\
\hline Primary radial nerve palsy & 15 & 40 \\
\hline Lesion of brachial artery & 1 & 3 \\
\hline Lesion of musculocutaneous nerve & 0 & 0 \\
\hline
\end{tabular}

In none of these patients was intraoperative examination of the nerve carried out. These 15 cases of primary radial nerve palsy manifested in $53 \%$ of patients $(n=8)$ as motor loss with characteristic drop hand. In seven (47\%) patients, additional sensory loss occurred. In relation to accident cause, $80 \%(\mathrm{n}=12)$ of palsy cases occurred as a consequence of traffic accidents. This was statistically significant ( $p=$ $0.01)$.

At the time of follow-up, complete palsy remission had taken place in $83 \%(n=12)$ of patients.

While accidents with high energy potential, e.g. traffic accidents, had a palsy rate of $72 \%$, it decreased to $15 \%$ in low energy accident mechanisms. This difference was statistically significant $(p=0.02)$.

Radial nerve lesion occurred most often (60\% of cases) when the fracture was localized in the middle third of the shaft, followed by $20 \%$ of cases localized in the distal third.

In $74 \%(n=28)$ of patients, indication for surgery was a directly preceding primary trauma. In seven patients (18\%), indication was pathological fracture, while in two patients 
$(5 \%)$, it was a repeat fall onto the arm. Mean incision to closure time was $74 \mathrm{~min}$ (range $30-200 \mathrm{~min}$ ).

\section{Results from Clinical Follow-Up}

Follow-up was carried out in average after 25 months. Of the 38 patients, $24(63 \%)$ could be assessed according to functionality and native radiology. All of the seven patients who had suffered pathological fractures and one patient with polytrauma have since died. None of the patients had experienced complaints with the fractured or the uninjured arm prior to the accident.

In total, $88 \%$ of all follow-up patients rated their treatment result as good to excellent. Three (13\%) patients rated it as moderate. There was no gender-specific difference.

$88 \%(n=21)$ of patients could reach with their operated arm behind the head, while $75 \%$ of patients could place the dorsum of their hand on their waste.

Complete freedom of pain on the site of surgery was reported by $33 \%(n=8)$ of follow-up patients. Nine $(38 \%)$ patients reported mild pain. Moderate pain was experienced by $25 \%(n=6)$ of patients, while one patient complained of severe pain.

In Constant Score activity tests, patients achieved 7 of 10 points on average. Twenty (83\%) patients reported symptom-free sleep. Full use of the arm for work as well as leisure activities was reported by 17 patients, respectively. Ninety-two percent of follow-up patients were able to reach above the head. The overall result regarding range of motion of the treated arm was 31 of 40 points on average (76\%). For the untreated arm, it was (95\%) points. Thus, the Constant Score of the affected side corresponded with $62 \%$ of scores of the unaffected side.

Twenty (83\%) follow-up patients were able to carry out all of the required exercises. Only three (13\%) patients were able to perform all internal rotation tasks, while $38 \%$ were able to carry out the eight-point task. Four patients were able to reach their waist with the back of the hand, a further five patients the lumbosacral junction and three patients the rump, resulting in an average result of 6 points.

Full level or $80 \%$ of strength, respectively, was regained by $79 \%$ of follow-up patients. On average, patients regained $84 \%$ of strength of the unaffected side. Mean Constant Score for affected side was $79 \%$ vs $98 \%$ of unaffected side.

Results obtained from patients with a low-energy accident mechanism were on average 6 points lower than results from patients with a high-energy accident mechanism. A summary of functional results in relation to cause of accident is shown in Table 3. Patients who were hit by a car as pedestrians achieved the second worst result with 63 points on average. Lowest score values were found in fractures of the middle third of the humerus shaft. Here, damage of the radial nerve occurred in $60 \%$ of cases.

Of the 24 follow-up patients, 12 had primary radial nerve palsy. In 10 cases (83\%), complete remission of sensory and motor loss occurred. None of the patients were explored later. Furthermore, posttraumatic lesion of the radial nerve had no negative effect on subsequent function of the arm
(Table 4). The result achieved by the 12 affected patients was on average better by 3 points.

Table 3. Functional Result in Relation to Cause of Accident

\begin{tabular}{|l|c|c|}
\hline Traffic accidents & $\begin{array}{c}\text { Constant Score of } \\
\text { Affected Side } \\
\text { Mean (n) } \\
\text { driver }\end{array}$ & $\begin{array}{c}\text { Constant Score of } \\
\text { Unaffected Side } \\
\text { Mean (n) }\end{array}$ \\
motorcyclist & $80(14)$ & $98(14)$ \\
& $84(5)$ & $99(5)$ \\
& $84(4)$ & $97(4)$ \\
cyclist & $87(2)$ & $98(2)$ \\
Spedestrian & $63(3)$ & $97(3)$ \\
\hline Household & $93(2)$ & $100(2)$ \\
\hline Work & $69(5)$ & $95(5)$ \\
\hline Fall from great height & $51(1)$ & $98(1)$ \\
\hline
\end{tabular}

Table 4. Influence of Primary Radial Nerve Palsy on Functional Result

\begin{tabular}{|l|c|c|}
\hline & $\begin{array}{c}\text { Constant Score of } \\
\text { Affected Side } \\
\text { Mean (n) }\end{array}$ & $\begin{array}{c}\text { Constant Score of } \\
\text { Unaffected Side } \\
\text { Mean (n) }\end{array}$ \\
\hline \hline No radial nerve palsy & $77(12)$ & $97(12)$ \\
\hline Primary radial nerve palsy & $81(12)$ & $99(12)$ \\
\hline
\end{tabular}

\section{DISCUSSION}

Choice of the best surgical method for fractures of the humerus shaft has been controversially discussed. While there is a clear endorsement for medullary nailing in the lower limbs, this therapy method has only been gradually applied in humerus shaft fractures, not least due to the fact that here, surgery indication is generally questioned [8]. The unreamed humerus nail (UHN) is a novel implant specifically designed for the upper arm.

In the present study, female patients were on average 13 years older than male patients. The average age of 59 years for female patients is possibly due to an osteoporosis-related increase in fracture risk in women after the menopause. This age distribution was also reported by Brehme and Siebert [9, 10]. In our patient cohort, we also found the gender-specific age structure as previously reported by Tytherleigh-Strong [11], with a peak age of $30-39$ years in male patients and $70-79$ years in female patients.

Considering the type of accident, $34 \%$ of patients, particularly men, suffered a polytrauma. These findings are in agreement with those of several other authors $[12,13]$. According to their mechanisms, the accidents can be divided into high-energy and low-energy trauma. High-energy traumas include traffic accidents or a fall from a great height, while low-energy traumas include household, sport or occupational accidents. In the present study, 18 accidents $(58 \%)$ were high-energy ones, mostly suffered by male patients. A similar frequency $(56 \%)$ was reported by 
Rommens [14], whereas Verheyden [15] observed only in $3 \%$ of his patients high-energy accident mechanisms. Most common fracture cause was traffic accidents (32\%) followed by household accidents $(24 \%)$, pathological fractures $(18 \%)$, falls from great height $(8 \%)$ and sport $(5 \%)$ and occupational accidents (3\%). Brehme [9] and Rommens [16] reported on the same order of fracture incidence for surgical therapy in their patients.

As with other authors, in the patient cohort of the present study, the fracture most often occurred in the middle third of the humerus shaft $[2,17]$.

Eighty-four percent of all fractures were closed ones. Of the open fractures, three were grade I and another three were grade III fractures. These percentages are above those reported in the literature (6\% reported by Blum [8], $6.1 \%$ by Brehme [9]). Only Marty [18] and Rommens [16] observed a frequency of $11 \%$. In their study - as with our patient cohort - the number of polytraumatized patients was higher than in other publications. All soft tissue injuries healed without complications.

Analysis of age distribution revealed that, with a balanced gender ratio, patients who suffered from palsy were, on average, 24 years younger than patients without palsy. Considering the relationship between cause of accident and palsy, a statistically significant traffic accident incidence of $80 \%$ was found with mostly younger patients affected. This explains the above mentioned age distribution. The same significant correlation was reported by Wawro [19].

A statistically significant difference was also found regarding trauma intensity. Thus, up to $70 \%$ of primary radial nerve palsy cases were associated with high-energy accident mechanisms involving more male (62\%) than female $(38 \%)$ patients. However, gender did not influence incidence of palsy since almost the same number of male and female patients suffered from it. Trauma intensity is probably crucial for generation of palsy lesion. Alnot and coauthors [20], who examined the relationship between accident mechanisms and type of radial nerve lesion, concluded that high-energy traumas often result in a transection of the nerve, while low-energy traumas only lead to nerve contusion.

Need for surgical revision of the radial nerve in primary and secondary palsy is still controversially discussed. Due to the high to absolute rate of spontaneous remission within the first hours and weeks, Böhler [2], in agreement with many others [10, 21-23], recommended the 'wait and see' approach. Under surgical examination, Sonneveld observed in 13 of 14 cases no nerve damage with subsequent spontaneous remission. Another argument against revision is the risk of additional iatrogenic nerve damage during examination, which occurs on average in $10 \%$ of cases [24]. Thus, Wawro [19] is also hesitant about immediate revision of the radial nerve. He reported a regression rate of $92 \%$ in 115 humerus fractures and would consider an exceptional indication for revision only in connection with cause of accident (high-energy trauma) or fracture localization. Primary palsy is mostly transient resulting from traction or bleeding, whereas direct transection occurs only exceptionally. For these reasons, Schratz [13] also does not warrant primar exploration. In case of no regeneration, early secondary revision should be carried out between eight and 16 weeks after the accident [11].

As radial nerve palsy remission is often not complete, but at a rate of $90 \%$, other authors argue - due to the remaining $10 \%$ - for rapid surgical exploration [7,19,25]. As advantages for early revision, its advocates list easier detection and better assessment of the nerve. They also consider the often months long wait with uncertainty, morbidity and unfitness for work unacceptable for the patient [26]. Highest rates of continuity interruption were reported by Siebert [10] with $26 \%$ of cases and Nast-Kolb [27] with irreparable nerve damage in $33 \%$ of cases. These authors consider primary and secondary palsy, especially in distally localized and complex fractures, a distinct indication for early surgical intervention and stabilization with plating. This is also the method of choice for Bonnaire [28].

In the University Clinics Bonn, Germany, all humerus shaft fractures were treated with UHN and without intraoperative examination of the radial nerve. At the time of follow-up, remission had occurred in $87 \%$ (13 patients) of cases. Of these, $12(80 \%)$ were complete. The palsy cases without complete remission improved after neurolysis was performed. Brehme [9] reported on spontaneous remission after UHN treatment in seven of nine cases.

Evaluation of subjective upper arm complaints showed that $21(88 \%)$ patients reported at least one complaint. Most often (67\%), interviewed patients complained about restriction of movement, followed by strength deficits (58\%), pain (50\%), meteorosensitivity (42\%) and paresthesia $(21 \%)$. Yet, in the surgically treated patients of the prospective study published by Nast-Kolb [24], most common symptoms were meteorosensitivity $(47 \%)$, followed by strength deficits $(40 \%)$, pain $(30 \%)$, paresthesia $(20 \%)$ and restriction of movement (16\%).

Additionally, patients were asked for their subjective assessment of the treatment result. This was considered to be good to excellent by $88 \%$ of follow-up patients. This result is higher than the $82 \%$ reported by Nast-Kolb [24] and lower than the $95 \%$ reported by Blum [8]. Of Bonnaire's patients treated with plating, 91\% assessed treatment results as excellent to good [28].

In the present study, a Constant Score of 79 points on average was achieved corresponding to $81 \%$ of the unaffected side. Loitz and co-authors [12] found in their study on retrograde medullary nailing a value of $87 \%$ for the unaffected side. In this patient cohort, the only genderspecific difference was the fact that female patients had on average a marginally better value by $2 \%$ on both sides.

Comparison of scores from high-energy and low-energy accident mechanisms initially reveals a contradictory result with higher values for high-energy traumas. This may be explained by the age distribution. High-energy traumas were suffered by two age groups, the 10-29 year olds and the 3039 year olds. As detailed above, results for the older age group were worse, while the younger group had excellent results with better accident recovery.

In summary it can be stated that in high-energy accident mechanisms, a higher Constant Score - hence a good general 
arm function - depends on age of the patient rather than strength of impact per se with worst prognosis for impact traumas. It also of decisive importance whether it was a mono- or a polytrauma. Patients who were able to start with physiotherapy directly after surgery had better results than polytraumatized patients who often had to remain in intensive care and could only start with limited physiotherapy. However, due to the small number of patients, these findings must be interpreted with caution.

\section{CONCLUSION}

The present study shows on the basis of clinical findings and follow-up results that $\mathrm{UHN}$ is a simple, minimal invasive method of rotation stable treatment of humerus shaft fractures. Due to the high rate of spontaneous remission, examination of the radial nerve in case of concomitant palsy is not required.

\section{CONFLICT OF INTEREST:}

None.

\section{REFERENCES}

[1] Shao YC, Harwood P, Grotz MR, Limb D, Giannoudis PV. Radial nerve palsy associated with fractures of the shaft of the humerus: a systematic review. J Bone Joint Surg Br 2002; 87: 1647-52.

[2] Böhler L. Against the operative treatment of fresh humeral shaft fractures. Langenbecks Archives Surgery 1964; 308: 465-75.

[3] Nast-Kolb D, Knoefel WT, Schweiberer L. The treatment of humeral shaft fractures. Results of a prospective $\mathrm{AO}$ multicenter study. Unfallchirurg 1991; 94: 447-54

[4] Seidel H. Humeral locking nail: a preliminary report. Orthopedics 1989; 12: 219-26.

[5] Tscherne $\mathrm{H}$, Oestern HJ. Technique and results of rigid-plate fixation in forearm fractures. Unfallheilkd 1982; 85: 111-6.

[6] Gustilo RB, Mendoza RM, Williams DN. Problems with the management of type 3 (severe) open fractures: a new classification of type 3 open fractures. J Trauma 1984; 24: 742-6.

[7] Constant CR, Murley AHG. A Clinical Method of the Functional Assessment of the Shoulder. Clin Orthop 1987; 214: 160-4.

[8] Blum J, Rommens PM, Janzig H, Langendorff HS. Retrograde nailing of humerus shaft fractures with the unreamed humerus nail. An international multicenter study. Unfallchirurg 1998; 101: 34252.

[9] Brehme K, Wawro W, Otto W. Unreamed Humerus nail (UHN): spectrum and results. Trauma Berufskh 2000; 2: 277-83.
[10] Siebert CH, Heinz BC, Höfler H-R, Hansis M. Plate osteosynthesis management of humerus shaft fractures. Unfallchirurg 1996; 99: 106-11.

[11] Tytherleigh-Strong G, Walls N, McQueen MM. The epidemiology of humeral shaft fractures. J Bone Joint Surg 1998; 80: 249-53.

[12] Loitz D, Könnecker H, Illgner A, Reilmann H. Retrograde intramedullary nailing of humeral fractures with new implants. Analysis of 120 consecutive cases. Unfallchirurg 1998; 101: 54350 .

[13] Schratz W, Wörsdörfer O, Klöckner C, Götze C. Treatment of humerus shaft fractures with different nail-systems (Seidel- nail, Marchetti-Vicenzi-nail, Prevot-Pins). Unfallchirurg 1998; 101: 127.

[14] Rommens PM, Verbruggen J, Broos PL. Retrograde locked nailing of humeral shaft fractures- a review of 39 patients. J Bone Joint Surg 1995; 77: 84- 9 .

[15] Verheyden P, Streidt A, Lill H, Weise K, Josten C. Unreamed Humerus nail- indication, technique and results. Akt Traumatol 1998; 28: 251-7.

[16] Rommens PM, Blum J. Retrograde Nailing of Fresh and Pathologic Humeral Shaft Fractures With a New Unreamed Humeral Nail (UHN). Techniques Orthopaedics 1998; 13: 51-60.

[17] Klestil T, Rangger C, Gföller P, Rieger M. Conservative treatment of humerus shaft fractures. Trauma Berufskrankh 2000; 2: 467-9.

[18] Marty B, Käch K, Friedl HP, Trentz O. Nailing of humerus shaft fractures. Unfallchirurg 1994; 97: 424-9.

[19] Wawro W, Brehme K, Otto W. Radial palsy in humerus shaft fractures- indication for revision? Trauma Berufskh 2000; 2: 284-7.

[20] Alnot J, Osman N, Masmejean E, Wodecki P Lesions of radial nerve in fractures of the humeral diaphysis. Apropos of 62 cases. Rev Chir Orthop Appar Mot 2000; 86: 143-50.

[21] Samardzic M, Grujicic D, Milinkovic ZB. Radial nerve lesions associated with fractures of the humeral shaft. Injury 1990; 21: 220-22.

[22] Sturzenegger M, Rutz M. Radial nerve paralysis--causes, site and diagnosis. Analysis of 103 cases. Nervenarzt 1991; 62: 722-9.

[23] Rommens PM, Vansteenkiste F, Stappaerts KH, Broos PLO. Indication and results of operative traeted humerus shaft fractures. Unfallchirurg 1998; 92: 556-70.

[24] Nast-Kolb D, Schweiberer L. Change in the treatment of humerus shaft fractures. Orthopädie 1989; 18: 208-13.

[25] Brug E, Joist A, Meffert R. Postoperative radial paralysis. Fate or negligence, conservative wait or revision? Unfallchirurg 2002; 105: $82-5$

[26] Brug E, Westphal T, Schäfers G. Differential treatment of diaphyseal humerus fractures. Unfallchirurg 1994; 97: 633.

[27 ] Nast-Kolb D, Ruchholtz S, Schweiberer L. Indication and technique in non-operative treated humerus shaft fractures. Akt Traumatol 1997; 27: 80-85.

[28] Bonnaire F, Götze B, Schlickewei W, Zenz M. Indication, technique and results of OSIF in humerus shaft fractures. Akt Traumatol 2001; 31: 82-9. 